\title{
Identifying Winners and Losers in Transportation
}

\author{
David Levinson
}

The issues surrounding transportation equity, both external and internal to transportation, are explored. Several examples are provided of transportation improvements that impose transportation costs on more individuals than those who are benefited. Beyond counting the number of winners and losers, several quantitative measures of equity are suggested and applied to a test case: ramp meters in the Twin Cities, Minneapolis-St. Paul, in Minnesota. It is recommended that transportation benefit-cost analyses include an "equity impact statement," which would consider the distribution of opportunities to participate in decisions and the outcomes of those decisions (in terms of mobility, economic, environmental, and health effects) that different strata (spatial, temporal, modal, generational, gender, racial, cultural, and income) of the population receive. Policy makers would then have additional information on which to base decisions.

Social welfare includes both efficiency and equity. Transportation engineers are taught to provide for the safe and efficient movement of people and goods. They are not taught to ensure that transportation systems are equitable, in part because of the ambiguity associated with equity. Transportation textbooks seldom broach the subject, which is considered political rather than technical. [Hanson's text (l) is a notable exception.] In economics, the words "equity" and "fairness" do not appear in the index of Varian's standard textbook, Microeconomic Analysis (2). Still, economics does not completely ignore the topic; Baumol devoted a book to Superfairness (3).

Public-sector investment decisions are made in nonmarket forums that often suffer from a short-term viewpoint and the dominance of selected individuals (4). For objectivity, public-sector investments generally rely on benefit-cost $(\mathrm{B} / \mathrm{C})$ analysis to compare various proposals. The use of $\mathrm{B} / \mathrm{C}$ analysis as a decision-making tool in public choices results in the separate consideration of equity and efficiency. Usually the efficiency criterion employed by decision makers for a project overrides concern for equity. A situation is considered pareto efficient (or pareto optimal) if there is no way to make all agents better off, that is, if one cannot improve person $\mathrm{Y}$ without worsening person Z. However, there are two problems with pareto efficiency. First, some things, such as time, are not fungible, making exchange difficult (someone cannot give you 10 minutes). Second, the exchange does not actually occur. Therefore, although the pareto criterion is important from an efficiency point of view, it is unhelpful in trying to understand equity.

Although transportation projects are formally planned on the basis of efficiency, equity criteria may affect the project. However, the concept of equity is highly subjective and changes with the individual concerned. A project that may appear equitable to the decision maker may not appear so to an individual affected by the project.

Department of Civil Engineering, University of Minnesota, 500 Pillsbury Drive SE, Minneapolis, MN 55455.
This situation makes it difficult to achieve objective decisions with respect to considerations of equity, but neither does it mean that equity can be ignored.

It is therefore necessary to use an approach that considers both efficiency and equity in the evaluation of public-sector investments. The use of both quantitative and qualitative approaches to equity would help give importance to those factors that are not included in $\mathrm{B} / \mathrm{C}$ analysis.

Questions of equity should be of concern to transportation analysts facing political issues whose resolution depends on perceptions of fairness. The most important problem in the analysis of equity has been the question of its definition. The term "equity" has both a descriptive (positive) and a normative use, describing the distribution of benefits and whether the distribution is for better or worse (5). Horizontal equity refers to the equivalent or impartial treatment of individuals with regard to the allocation of the benefits and costs among individuals and groups who are similar in terms of wealth and ability $(6,7)$. Vertical equity, however, refers to the distribution of benefits and costs among different income groups or other strata such as physical disability.

From the normative point of view, there are two additional concepts. Equality of opportunity, or process equity, is concerned with equal access to the planning and decision-making process. In contrast, equality of outcome, or result equity, examines the consequences of the product. The U.S. Constitution enshrines the first, whereas the Declaration of Independence only posits the right to pursue happiness, not happiness itself. In contrast to the utilitarian aim to maximize total welfare, the egalitarian view would maximize the welfare (or opportunities) of the least advantaged member of society, and thus move society toward greater equity, as championed by the environmental justice movement $(8,9)$. Compared with the wealthy, the poor spend a larger portion of their income on transportation (as well as a variety of other goods). Furthermore, the poor and disadvantaged have historically borne the burden of transportation investments and improvements, which are often sited in their neighborhoods (10, pp. 190-234).

The recent slow pace of additions to the transportation network, as illustrated in Figure 1, has in part been blamed on increasing opposition to new construction. The neighboring opponents, often termed NIMBYs, for Not In My Back Yard, are accused of selfishness, people who would place their own needs above those of the rest of the community. An addition to the transportation network that moves people from $\mathrm{A}$ to $\mathrm{B}$ often must cross $\mathrm{C}$ to get there. If the project harms or disadvantages the people living near $\mathrm{C}$, and if they are uncompensated, it is perfectly reasonable for them to oppose expansion. Their opposition is sometimes claimed to be because of the negative externalities of transportation (noise, air pollution, etc.), which are increased in the locality of the project. However, the opposition may also reflect a sense that the project will make them worse off in mobility terms. It is seldom acknowledged (though 
Highway Miles,

Vehicle Miles Traveled

('000)

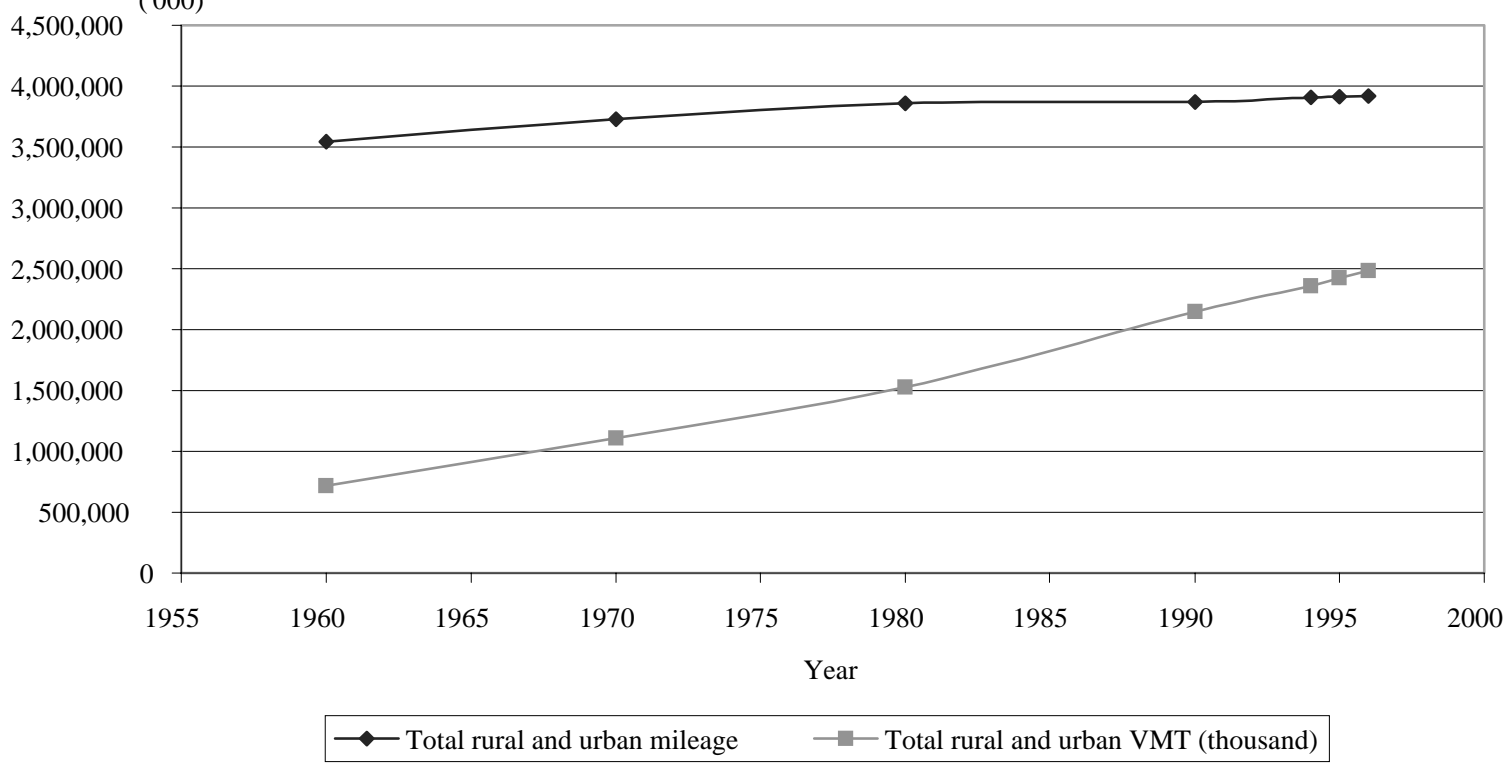

FIGURE 1 Growth in network and traffic, 1955-1997.

occasionally claimed to be obvious) that many transportation projects and policies increase the travel times of some travelers in order to decrease the times of others. Those travelers who lose from the improvement may also be automobile commuters making local trips, or they may be pedestrians now forced to use an overpass or tunnel, or transit users placed on a more circuitous route.

Any new transportation project or policy creates both winners and losers from the standpoints of mobility, accessibility, and environmental and economic concerns. In some cases, an improvement does not even make society better off as a whole; the gains of the winners do not exceed the losses of the losers. Whether society gains overall depends on both the shape of the network and the elasticity of demand. Thus there may be a great deal of conflict around new construction or policy changes, in which the losers attempt to use the political process to stop projects that may have an overall net benefit to society. In this paper, methods for measuring gains and losses are developed. It is hoped that this information can be used to create situations in which the losers are compensated rather than excluded from the process.

The issues surrounding transportation equity are explored. The external effects are investigated first. Next some examples are presented to illustrate how transportation improvements may create winners and losers. These results are due to the coupling inherent in transportation networks. Changes to capacity on one link change the patterns of demand (and the implicit supply) on others. Quantitative measures of equity are suggested and applied to a case study of ramp meters in the Twin Cities of Minneapolis-St. Paul, in Minnesota. These measures can be used in an equity impact analysis to determine explicitly the distribution of gains and losses across subpopulations.

\section{EXTERNAL INEQUITIES}

Costs borne directly by consumers are considered internal costs. The costs of a transaction that are borne by third parties are termed external costs. The definitions distinguish harm committed between strangers, which is an external cost, and harm committed between parties to an economic transaction, which is an internal cost. When external costs are estimated, one can use either the estimated amount of economic damage (including both market and nonmarket costs) produced by the externality or the cost of preventing that damage in the first place. Rational economic actors would choose the lower of prevention costs or damage costs when costs are internalized. If there were a cheaper prevention measure, it could be used, but if prevention were more expensive, the actors would accept damages.

Levinson and Gillen (11) proposed a full-cost model including user costs, infrastructure costs, and external costs, without doublecounting transfers (e.g., user taxes for infrastructure or automobile insurance). Estimates of that model for a specific set of assumptions for intercity highway travel in California are given in Table 1. (The costs, particularly for travel time, shown in Table 1 can be expected to be lower than those found in urban regions.) Although internal costs are much larger than external costs, the external costs are significant and measurable. These costs are only a portion of total external costs, since there are some costs that cannot be easily monetized. Social severance is the cost of dividing communities with infrastructure. It is a real externality, but its valuation is difficult.

TABLE 1 Long-Run Average Costs by Category (11)

\begin{tabular}{ll}
\hline Cost Category & $\begin{array}{l}\text { Long Run Average Cost } \\
(\$ / \mathrm{vk})\end{array}$ \\
\hline User & 0.13 \\
Infrastructure & 0.0174 \\
Free Flow Time & 0.15 \\
Congestion & 0.0045 \\
Accidents & 0.031 \\
Noise & 0.006 \\
Air Pollution & 0.0056 \\
Total & 0.34 \\
\hline
\end{tabular}


Another important cost is ecosystem severance, the environmental cost from placing a highway amidst native ecologies. Costs such as the defense of the Persian Gulf, parking, or urban sprawl have been suggested by other researchers, but whether these costs should be counted is subject to significant disagreement.

From the perspective of investigating winners and losers, clearly the recipients of those external costs are losers; they need to be either persuaded (or required) to take the loss for the good of society or compensated through some type of side payment or bargain in order to obtain their acquiescence to new infrastructure that would impose such heavy costs. In principle those external costs could be offset by external benefits from transportation, but no good quantification of those external benefits has yet been made (12).

\section{MOBILITY INEQUITIES}

Generally, in the case of fixed (inelastic) demand, the addition or expansion of a link will make the travelers on that link better off and nobody else worse off. However, even for that situation there is a famous counterexample. Braess's paradox (13) shows that in a simple network serving one origin and one destination, an additional link can worsen overall welfare if travelers behave according to the Wardrop user equilibrium principle (i.e., they travel on the shortesttime path, given that everyone else is doing likewise). Since research has shown that demand is induced by capacity expansions $(14,15)$, the assumption of inelastic demand is clearly unreasonable.

Here several additional examples are developed of how transportation improvements create both winners and losers. These cases are not a complete set but simply are intended to illustrate some of the issues involved and to suggest where the resentment toward new transportation projects may come from.

In dealing with multiple markets, the issue of coupled supply and demand arises. In transportation, markets can generally be thought of as origin-destination pairs. A coupled market is one in which a change in the supply or demand in one market changes the supply or demand curve for another market. In coupled markets, a careful examination is required before conclusions about net and specific benefits can be deduced. Coupling implies a nonzero cross-elasticity of demand (or price) with respect to a change in price (or demand) in another market.

\section{Example 1: Y-Network}

To begin, a very simple network, shown in Figure $2 a$, is assumed. An improvement to link $J-D_{1}$ may have several effects, depending on the assumptions that are made about demand elasticity. In all cases it is assumed that the travel time functions on links $J-D_{1}$ and $J-D_{2}$ are an increasing function of demand.

1. Inelastic trip production and attractions: If the number of trips produced at $O$ is fixed and the number of trips attracted to $D_{1}$ and $D_{2}$ is also fixed, nothing happens except that travelers from $O$ to $D_{1}$ see an improvement in travel time. An example of this effect in the short term is when $O$ represents work trips originating at home and $D_{1}$ and $D_{2}$ represent job sites.

2. Inelastic trip production and elastic trip attractions: If trip origins remain fixed but there is no constraint on destinations, some or all travelers from $O$ to $D_{2}$ will switch to $O$ to $D_{1}$. An example of this effect is when $O$ represents shopping trips originating at home and

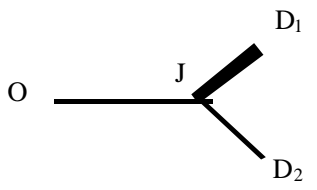

(a)

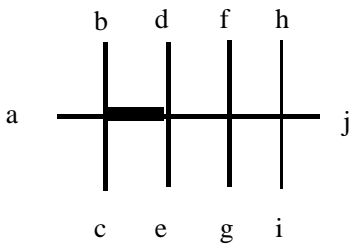

(b)

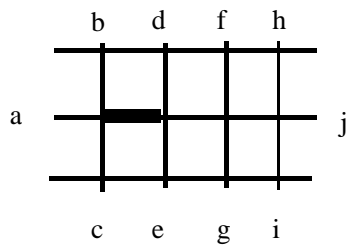

(c)
FIGURE 2

Example networks.
$D_{1}$ and $D_{2}$ represent otherwise identical supermarkets, and there is no capacity constraint at the supermarkets. $O-D_{1}$ has a relative accessibility improvement over $\mathrm{O}-\mathrm{D}_{2}$, though in fact both improve in absolute terms compared with before the improvement.

3. Elastic trip productions and attractions: If it is assumed that demand is sensitive to supply for both origins and destinations, the improvement will increase demand from $O$ to $D_{1}$ as the price for those trips declines. This effect will inevitably increase flows on the unimproved link $O-J$. This additional flow will worsen travel times (and reduce demand) from $O$ to $D_{2}$.

\section{Example 2: Network Bridge}

The degree of substitution and complementarity will determine to what extent losers are created by a change relative to the number of winners. In the Example 2 network (Figure $2 b$ ), with $n=10$ origins and destinations, there are $n(n-1)=90$ markets (ignoring internal trips). Assuming fixed demand, improving the bridge link (heavy dark line) will improve all of the trips using the bridge link (42) and leave the other 48 markets unchanged. Assuming elastic demand, the 42 improved markets will see growth in traffic, which will worsen travel times in the other 48 markets (as seen in Table 2) because of downstream congestion. Although there may very well be a net benefit, the number of beneficiaries is potentially less than the number of losers.

\section{Example 3: Grid Network}

In contrast to the bottleneck bridge, expanding a link on a grid will have a larger share of winners, as illustrated in Figure $2 c$. Revising Example 2 and assuming elastic demand, each of the forty-two 
TABLE 2 O-D Pairs for Example 2

\begin{tabular}{lllllllllll}
\hline & $\mathrm{a}$ & $\mathrm{b}$ & $\mathrm{c}$ & $\mathrm{d}$ & $\mathrm{e}$ & $\mathrm{f}$ & $\mathrm{g}$ & $\mathrm{h}$ & $\mathrm{i}$ & $\mathrm{j}$ \\
\hline $\mathrm{a}$ & $\mathrm{x}$ & 0 & 0 & 1 & 1 & 1 & 1 & 1 & 1 & 1 \\
$\mathrm{~b}$ & 0 & $\mathrm{x}$ & 0 & 1 & 1 & 1 & 1 & 1 & 1 & 1 \\
$\mathrm{c}$ & 0 & 0 & $\mathrm{x}$ & 1 & 1 & 1 & 1 & 1 & 1 & 1 \\
$\mathrm{~d}$ & 1 & 1 & 1 & $\mathrm{x}$ & 0 & 0 & 0 & 0 & 0 & 0 \\
$\mathrm{e}$ & 1 & 1 & 1 & 0 & $\mathrm{x}$ & 0 & 0 & 0 & 0 & 0 \\
$\mathrm{f}$ & 1 & 1 & 1 & 0 & 0 & $\mathrm{x}$ & 0 & 0 & 0 & 0 \\
$\mathrm{~g}$ & 1 & 1 & 1 & 0 & 0 & 0 & $\mathrm{x}$ & 0 & 0 & 0 \\
$\mathrm{~h}$ & 1 & 1 & 1 & 0 & 0 & 0 & 0 & $\mathrm{x}$ & 0 & 0 \\
$\mathrm{i}$ & 1 & 1 & 1 & 0 & 0 & 0 & 0 & 0 & $\mathrm{x}$ & 0 \\
$\mathrm{j}$ & 1 & 1 & 1 & 0 & 0 & 0 & 0 & 0 & 0 & $\mathrm{x}$
\end{tabular}

1 indicates improved, 0 otherwise, $x$ unaffected, 42 improved OD pairs

directly improved markets will still see growth in traffic, though others may as well. In this example, traffic is now able to reroute, so other markets, which do not use the improved link, may benefit as well. For instance, trips from $d$ to $f$ and from $d$ to $h$, which in Example 2 mixed with traffic from $b$ to $j$ and $b$ to $g$ and $b$ to $i$, may benefit because some fraction of the $b$-originating traffic shifts southward to take advantage of the improvement. In this particular example, the number of beneficiaries now exceeds the number of losers.

\section{MEASURING EQUITY}

Beyond a simple count of the number of winners and losers, richer, more systematic measures of equity can be developed. The Gini coefficient of concentration and the Lorenz curve have historically been used to measure the equality in the distribution of a good. These tools have been used in economics to analyze income inequality. The distribution of the total income is represented by the Lorenz curve, and the statistical analysis is done using the Gini coefficient, which is hence a measure of the degree of inequality.

The Lorenz curve is the line separating the $A_{1}$ and $A_{2}$ areas in Figure 3. The Lorenz curve relates the proportion of the population receiving a given proportion of income. Whereas the bottom $100 \%$ of the population gets $100 \%$ of the income by definition, the bottom $50 \%$ may only get $30 \%$ of the income. The Gini coefficient is the ratio $A_{1} /\left(A_{1}+A_{2}\right)$. A Gini coefficient of 0.0 indicates perfect equal-

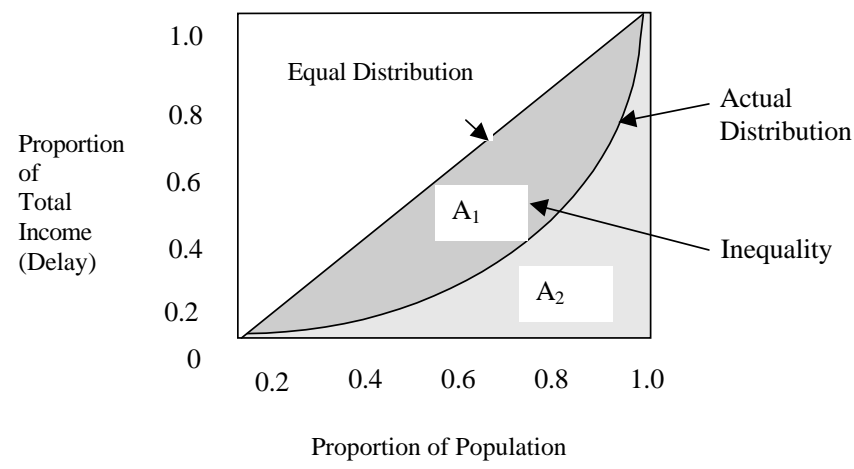

FIGURE 3 Gini coefficient and Lorenz curve. ity, and 1.0 indicates perfect inequality (the richest person gets all). For the income in the United States, according to 1994 census results, the Gini coefficient was 0.456 .

The Lorenz curve concept can be used to measure other kinds of equity, not just income, by changing what is shown on the $Y$-axis. For instance, rather than income, it could be frequency of bus service on the nearest route or delay at ramp meters (though here the best outcomes are at the left of the $X$-axis rather than to the right). In general, any type of quantifiable impact, market or otherwise, can be assessed with this type of measure. Although it may not be efficient to aim for a Gini coefficient of zero, the change in the coefficient before and after a project gives some sense of whether the project is equity enhancing or equity subtracting.

The entropy statistic $(H)$ focuses on the evenness of the distribution. An alternative is said to be equitable the closer it is to an equal distribution of net gains:

$$
H=-\sum_{j}\left(y_{j} \cdot \log _{k} y_{j}\right)
$$

where

$$
\begin{aligned}
H & =\text { entropy statistic, } \\
y_{j} & =\text { proportion of average net gains to } j \text { th class, and } \\
k & =\log \text { base. }
\end{aligned}
$$

To analyze traffic data, $y_{i}$ equals the proportion of total delay accrued by each individual [or on each link or for each origin-destination (OD) pair, etc.].

The computed $H$-statistic approaches zero as the distribution approaches complete inequality. The computed $H$-statistic gets larger as the distribution moves toward equality. For historical reasons arising from its emergence in information theory, log base 2 has been the most widely used in the computation of the entropy statistic. Another measure that has been used is the redundancy statistic, $R$, which calculates the bias in the distribution as opposed to the index of equality measured by the entropy statistic, $H$.

An $R$-value of $0 \%$ represents complete equality in distribution, or lack of bias. An $R$-value of $100 \%$ represents complete inequality, or bias in favor of one class. The equality in the average marginal utility of net change in real income is the third measure of equity:

$R=1-\frac{H}{H_{\max }}$

where

$$
\begin{aligned}
R & =\text { measure of redundancy } \\
H & =\text { calculated entropy, and } \\
H_{\max } & =\text { maximum possible entropy. }
\end{aligned}
$$

\section{RAMP METERS}

In fall 2000, the ramp meters in the Twin Cities were turned off for 8 weeks so that an assessment of their effectiveness could be made. Although this assessment focused on the efficiency of the system, considering mobility and safety particularly, a transportation equity analysis of the delay distribution across space could also be made. In this section the relationship is estimated between mobility and equity for O-D pairs on Route 169, a suburb-to-suburb limitedaccess highway connecting the north and south legs of the region's beltway, with and without ramp meters. In order to make the results 
comparable, the data used for the analyses (ramp metering on and off) were collected on Tuesday, March 21 and November 7. November 7 is the third Tuesday after the ramp meters were shut down. The calculation methodology is described more fully elsewhere (16). It is assumed that an equilibrium was established and that traffic patterns were stable after 3 weeks.

In this discussion the equity and mobility for specific trips are considered. The mobility measures include total travel time, speed, and delay. All the measures are computed for each 5-min interval for each OD pair. Since the number of trips on each OD pair is not available, all the averaging is done without weighting by number of trips between origin and destination. The analysis is performed for 105 OD pairs.

What ramp meters bring in terms of mobility and equity can be shown by the comparison of the two cases. Previous research indicates that ramp meters can increase the mobility of freeway networks, which is confirmed by the findings here. With ramp metering, the average travel speed (taking ramp delay into account) of the highway increases from $60 \mathrm{mph}$ to $100 \mathrm{mph}(37 \mathrm{~km} / \mathrm{h}$ to $62 \mathrm{~km} / \mathrm{h})$; travel delay per mile decreases from $136 \mathrm{~s}$ to $112.5 \mathrm{~s}$ and the average travel time for one trip decreases from $610 \mathrm{~s}$ to $330 \mathrm{~s}$.

No previous results can be relied on to guide this analysis of equity. In contrast with the consideration of freeway segments in the previous section, when one looks at trips, one finds a drop in the Gini coefficient in the absence of metering. This result suggests that the system becomes more fair when meters are removed. This drop is observed for three primary measures: travel time per mile, travel speed, and travel delay per mile.

Figure 4 illustrates the trends in the change of mobility and equity with and without metering for trips. It should be noted that in Figure 4, the shortest trips (those on the right side of the graph) actually are hurt in mobility terms by ramp metering, whereas the longest trips (those on the left side) benefit the most.

\section{EQUITY IMPACT STATEMENT}

Environmental justice is a good beginning, but it only considers "fair treatment for people of all races, cultures, and incomes" regarding the development of environmental laws and policies (17). It thus only examines environmental outcomes and only addresses a few strata.

There are ways of grouping the population to determine the fairness of the distribution of gains and losses to specific subpopulations. Different groupings of the population will result in different assessments of a project's fairness. Because there is no right way of grouping, multiple groupings should be considered. To that end, transportation B/C analyses should include an "equity impact statement." [The Applied Research Center (18) has also developed what they call an equity impact statement; however, that document is a qualitative approach to assessing equity and can be seen as complementary to what is being suggested here. The city of Toronto, Canada (19), has issued an equity impact statement but again of a more qualitative and less systematic type than that suggested here.] This document would specifically consider the winners and losers for a project. In particular, a set of specified subgroups would be identified. Then the outcomes of the project (e.g., travel time and delay, accessibility, consumer's surplus, air pollution, noise pollution, accidents) would be assessed for each of the population groups. Although inequity across some dimensions is almost inevitable, it is crucial both for fairness and for political expediency, given the grow-
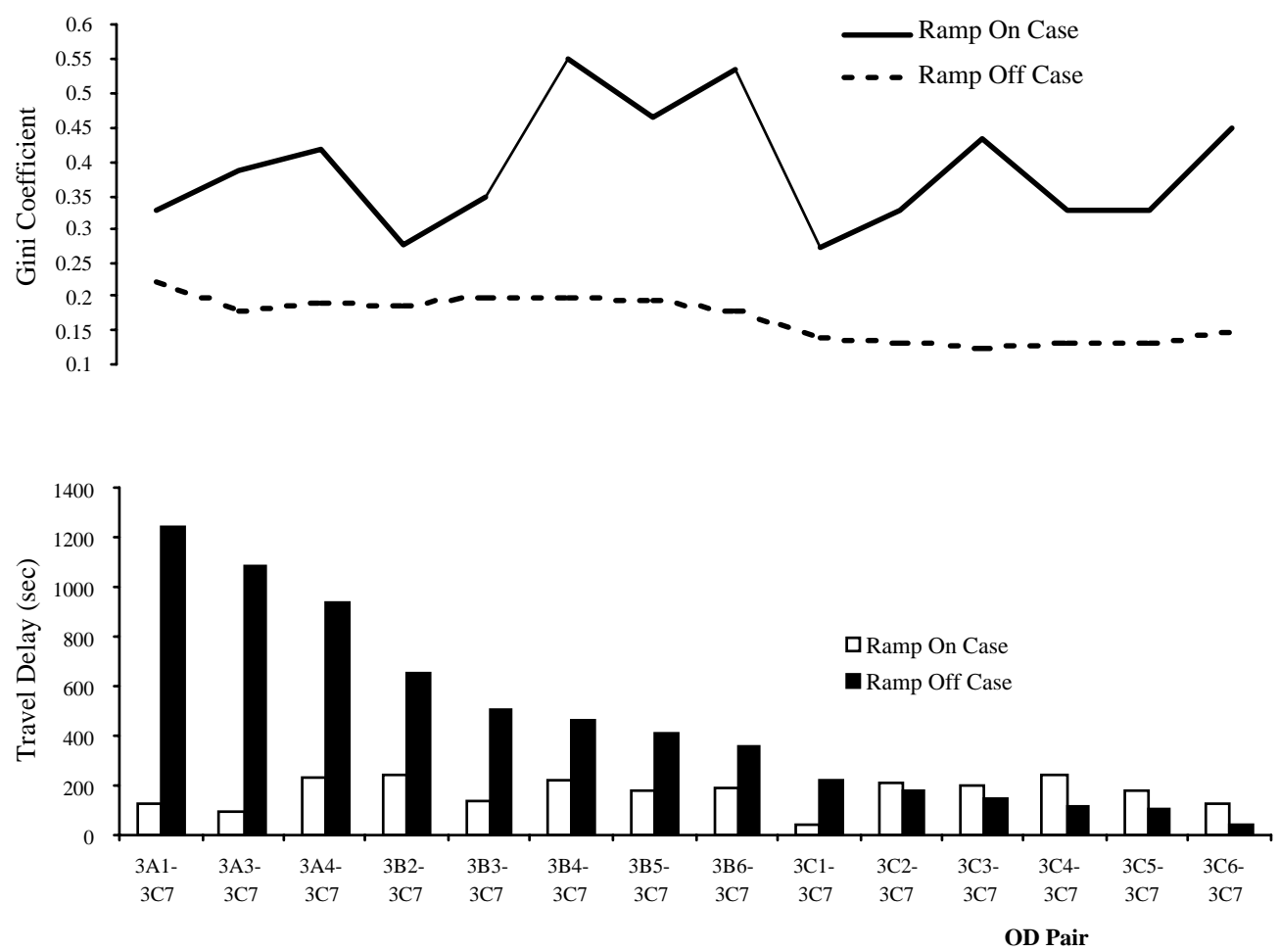

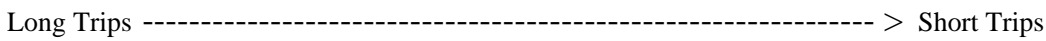

FIGURE 4 Relationship between temporal equity and mobility (travel delay), Route 169. 
ing environmental justice movement, to acknowledge the inequity and its relative magnitude before a project is implemented.

Chen (20) argues that the principles of social equity and environmental justice can be realized only when the conventional top-down approach to decision making ends. The only way that this can be done is by including all the groups of the community in the decisionmaking process. Social equity can be realized only when the needs of all groups are adequately represented. This argument calls for an inclusion of opportunity to participate as a key criterion in an equity impact statement. For each group, identification of whether that group had equal opportunity to affect the project would be made. Questions would be raised such as "Was the group included among the analysts and decision makers in proportion to its share of the affected population?" Although state departments of transportation and metropolitan planning organizations are attempting to involve minority and low-income populations to a larger degree, historical biases remain.

The equity impact statement, a checklist for which is given in Table 3, would thus consider the inputs (the opportunity to participate in decision making) as well as the outcomes (mobility, economic, environmental, health, and other) for transportation projects. The strata are worth discussing in some detail:

- The population stratification just looks at the population as a whole and investigates how equally distributed are both the opportunities to participate and the outcomes.

- The spatial (or jurisdictional) stratification would examine how different areas (from small areas like census blocks or traffic zones to larger areas like census tracts, jurisdictions, or metropolitan areas) are affected by the project. For example, the U.S. Congress has a House of Representatives, whose seats are allocated in proportion to population, and a Senate, which has two seats for every state. One ensures population equity, the other a type of spatial equity.

- The temporal stratification would consider the benefits and losses to current residents in comparison with those of (potential) future residents. Many transportation and land use policies, such as impact fees, have significant temporal effects (21).

- Modal equity considers whether users of different modes (e.g., drivers, pedestrians, transit riders) receive different gains or losses from a project and had equal input into the decision.
- Generational equity differentiates individuals by age: do the elderly or middle-aged benefit at the expense of the young?

- Gender equity contrasts men and women. Because there are known differences in the transportation use patterns by sex, distinguishing the effects on the two groups is important.

- Ability compares the fairness accorded to those without any physical or mental disability with the fairness to those facing such challenges.

- Racial and cultural equity consider the effects on different races, ethnic groups, religions, and cultures. Insufficient research has to date examined the transportation uses by these groups, but if only because of historic spatial segregation, transportation investments will have differential impacts.

- Similarly, some investments that serve certain vehicle types and certain areas will inevitably favor the rich over the poor, an issue addressed by examining income equity.

It must be recognized that collecting such data may be difficult or costly. Some data, such as income, race, or sex, may be known geographically (from census data) but not according to network use (which can only be estimated with models). Further, there will inevitably be the need to forecast when land use changes are anticipated. There may also be privacy concerns if some of these data are collected on facilities. Nevertheless, reasonable attempts can be made to estimate this information in a consistent way across alternatives so that general trends can be assessed.

\section{CONCLUSIONS}

A healthy skepticism by concerned citizens toward transportation projects is warranted on the basis of both the transportation and the external effects such projects have. It is no longer enough to apply the pareto maxim that so long as the losers could be compensated by the winners, the project is worthwhile. In the absence of such compensation, political opposition will continue to rise and new construction will continue to be more and more difficult.

Philosopher John Rawls (22) discusses the conditions for a fair outcome. He imagines two individuals shrouded in a "veil of ignorance"; they know what they prefer but don't know things like their

TABLE 3 Equity Impact Statement Checklist

\begin{tabular}{|c|c|c|c|c|c|c|}
\hline & Process & & & Outcomes & & \\
\hline Stratification & $\begin{array}{l}\text { Opportunity to } \\
\text { Engage in } \\
\text { Decision-Making }\end{array}$ & Mobility & Economic & Environmental & Health & Other \\
\hline $\begin{array}{l}\text { Population } \\
\text { Spatial } \\
\text { Temporal } \\
\text { Modal } \\
\text { Generational } \\
\text { Gender } \\
\text { Racial } \\
\text { Ability } \\
\text { Cultural } \\
\text { Income }\end{array}$ & & & & & & \\
\hline
\end{tabular}

NoTE: This checklist is suggestive of the considerations that should be explicitly taken. To apply this checklist, each cell should be considered. E.g. taking spatial/opportunity cell, we can ask a set of questions: Was the opportunity to engage in decision making fair across all jurisdictions (locales within a jurisdiction)? Did each place have a say in the planning, engineering, public meetings, financing, and final decision process? To what extent were small places given a voice equal to large? To what extent were populous areas given a voice in accord with their population? 
social class. They must agree to divide some spoils (political rights, money, etc.) but don't know which side of the spoils they will get. Rawls argues that they will come to a fair agreement because each has an equal possibility of receiving either side of the division. Rawls's approach is just a sophisticated version of the pie-cutter problem. Imagine that there is a pie and several $(N)$ people: how do you ensure that each gets an equal share? The solution is to let one person cut the pie into $N$ pieces, but the person who cuts the pie gets the $N$ th piece. He will ensure that the pieces are as equal as possible in order to get that last piece. However, the pie-cutter problem assumes a zero-sum world, whereas often there are gains from trade. Solutions to equity problems include ideas such as bundling improvements, so that not only is there a net benefit (when all projects are considered together), but the number of winners exceeds the number of losers by a significant amount.

Because of the sensitivity of equity analysis to the units of measurement and the definition of the groups, it becomes difficult to select a single, right method of evaluation. The method of equity analysis must be based on the community aspirations and needs. Leaving aside what is the "right" thing to do, consideration of equity is the efficient thing to do in a political environment that empowers many disparate groups. An equity impact statement or its equivalent could help to clarify the impacts of a policy or infrastructure proposal and to test alternative strategies. Equity considerations should be given consideration just as efficiency has traditionally been considered in transportation. Decisions are not made by society based on equity alone or efficiency alone, but rather some mix. Improving the measurement of both equity and efficiency can only lead to better decisions.

\section{ACKNOWLEDGMENT}

The author would like to thank Pavithra Parthasarathi and Lei Zhang for their research assistance on this paper. This research was conducted as part of the project Measuring the Equity and Efficiency of Ramp Meters, funded by the Minnesota Department of Transportation.

\section{REFERENCES}

1. Hanson, S. Geography of Urban Transportation. Guilford Press, New York, 1995.

2. Varian, H. Microeconomic Analysis, 3rd ed. W.W. Norton \& Company, New York, 1992.
3. Baumol, W. Superfairness. MIT Press, Cambridge, Mass., 1986.

4. Sagner, J. Benefit/Cost Analysis Efficiency-Equity Issues in Transportation. Logistics and Transportation Review, Vol. 16, No. 4, 1980, pp. 339-388.

5. Lee, D. B., Jr. Making the Concept of Equity Operational. In Transportation Research Record 677, TRB, National Research Council, Washington, D.C., 1978, pp. 48-53.

6. Khisty, C. J. Operationalizing Concepts of Equity for Public Project Investments. In Transportation Research Record 1559, TRB, National Research Council, Washington, D.C., 1996, pp. 94-99.

7. Litman, T. What is Transportation Equity? Community Transportation Reporter, Vol. 14, No. 7, 1996, pp. 22-23.

8. Stolz, R. Race, Poverty and Transportation. Poverty and Race, March/ April, 2000. Reprinted at www.communitychange.org/transportation/ raceandtransportation.asp. Accessed Oct. 18, 2001

9. Bullard, R., and G. Johnson, eds. Just Transportation: Dismantling Race and Class Barriers to Mobility. New Society Publishers, Gabriola Island, B.C., Canada, 1997.

10. Altshuler, A. The Intercity Freeway. In Introduction to Planning History in the United States (D. A. Krueckeberg, ed.), Center for Urban Policy Research, Rutgers University, New Brunswick, N.J., 1983.

11. Levinson, D., and D. Gillen. The Full Cost of Intercity Highway Transportation. Transportation Research, Vol. 3D, No. 4, 1998, pp. 207-223.

12. Rothengatter, W. Do External Benefits Compensate for External Costs of Transport? Transportation Research, Vol. 28A, No. 4, 1994, pp. 321-328.

13. Murchland, J. D. Braess's Paradox of Traffic Flow. Transportation Research, Vol. 4, 1970, pp. 391-394.

14. Hansen, M., and Y. Huang. Road Supply and Traffic in California Urban Areas. Transportation Research, Vol. 31A, No. 3, 1997, pp. 205-218.

15. Noland, R. Relationships Between Highway Capacity and Induced Vehicle Travel. Transportation Research, Vol. 35A, No. 1, 2001, pp. 47-72.

16. Levinson, D., L. Zhang, S. Das, and A. Sheikh. Measuring the Equity and Efficiency of Ramp Meters. Presented at the 81st Annual Meeting of the Transportation Research Board, Washington, D.C., Jan. 2002.

17. Executive Order 12898 About Environmental Justice. Office of Solid Waste and Emergency Response, Environmental Protection Agency, 1994. www.epa.gov/swerosps/ej/aboutej.htm. Accessed Oct. 18, 2001

18. Developing an Equity Impact Statement: A Tool for Local Policy Making. Applied Research Center, Grass Roots Innovative Policy Program, 1999. www.arc.org.

19. Diversity Our Strength: Access and Equity Our Goal, Appendix G: Access and Equity Impact Statements. Reports to Council Committees. Toronto City Council, 2001. www.city.toronto.on.ca/getting_around/ index.htm.

20. Chen, D. Social Equity, Transportation, Environment, Land Use, and Economic Development: The Livable Community. www.fta.gov/library/ policy/envir-just/backcf.htm. Accessed Oct. 18, 2001.

21. Levinson, D. Financing Infrastructure over Time. Journal of Urban Planning and Development, ASCE, Vol. 127, No. 4, 2001, pp. 146-157.

22. Rawls, J. A Theory of Justice, rev. ed. Belknap Press, Cambridge, Mass., 1999.

The opinions and errors in this paper remain those of the author.

Publication of this paper sponsored by Committee on Transportation Economics. 